\title{
POLYSENSITIZATION TO AEROALLERGENS IN PATIENTS WITH NASOBRONCHIAL ALLERGY IN KASHMIR VALLEY
}

\author{
ROOHI RASOOL ${ }^{1}$, AYAZ GULL ${ }^{2}$, DURI MATEEN YETOO ${ }^{3}$, QURTEEBA QADRI $^{4}$, \\ TAHA ASHRAF ${ }^{5}$, SYED SHAFIA $^{6}$ \& ZAFAR AMIN SHAH ${ }^{7}$ \\ ${ }^{I}$ Additional Professor, Department of Immunology \& Molecular Medicine, Sher-i- \\ Kashmir Institute of Medical Sciences, Soura, Srinagar, Kashmir, India \\ ${ }^{2,3,4,6,7}$ Department of Immunology \& Molecular Medicine, Sher-i-Kashmir Institute of \\ Medical Sciences, Soura, Srinagar, Kashmir, India \\ ${ }^{5}$ Department of Clinical Biochemistry, Sher-i-Kashmir Institute of Medical
}

Sciences, Soura, Srinagar, Kashmir, India

ABSTRACT
Background
The role of aeroallergens in the sensitization and progression of allergies is significant and differs in different
geographical regions. The aim of this study is to recognize the potential aero allergens and the degree of poly sensitization
that are responsible for causing naso bronchial allergies in Kashmir.
Materials \& Methods
$\quad 555$ patients were recruited for this study from Allergy Clinic, Sher-i- Kashmir Institute of Medical Sciences. A
standard prick test panel consisting of aeroallergens, dust mites, Fungi, pollens, dust mixture, epithelia \& insects was
used along with positive and negative control.
Results: Skin prick test results showed negative results in 47 patients, while remaining 508 showed positive results. All
the patients showed poly sensitization to various allergens; with dust mite and pollens as the most common allergens.
Conclusions
$\quad$ This study helped to understand the role of poly sensitization to common allergens responsible for respiratory
allergy to plan allergen specific immunotherapy in such patients.
KEYWORDS: SPT: Skin Prick Testing, IgE: Immunoglobulin E, BA: Bronchial Asthma \& AR: Allergic Rhinitis

Received: Aug 04, 2017; Accepted: Aug 21, 2017; Published: Aug 30, 2017; Paper Id.: IJESROCT20172

\section{INTRODUCTION}

Atopic diseases can manifest themselves at different sites on the body and can present as urticaria, allergic rhinitis, atopic dermatitis, conjunctivitis, food allergy, and asthma. Asthma and rhinitis are frequently associated with atopy with preferential sensitization to airborne allergens.

Over $20 \%$ of the world population suffers from immunoglobulin E (IgE) mediated allergic diseases such as asthma, rhino conjunctivitis, eczema and anaphylaxis [2].Allergic rhinitis constitutes $>50 \%$ of all allergies in India [3]. It is the most common allergic disorder worldwide, and one among the leading chronic conditions affecting both children and adults [4]. A recent survey carried out in India shows that 20-30\% of the population suffers from 
allergic rhinitis and that $15 \%$ develop asthma [5] indicating the rising trend. The prevalence of nasobronchial allergy has increased in last two to three decades possibly due to change in indoor and outdoor environment [6]. Both bronchial asthma(BA) and allergic rhinitis (AR) frequently coexist and are now thought to be a continuum of inflammation involving one common airway [7].Allergic rhinitis is a recognized risk factor for bronchial asthma, with 20\%-30\% of such patients having bronchial-asthma; conversely $60 \%-80 \%$ of patients with bronchial asthma have coexisting AR[8,9]. The frequent co-existence of rhinitis and asthma (up to $80 \%$ of asthmatic patients have co-existing allergic rhinitis, while up to $40 \%$ of allergic rhinitis patients have asthma, lead to the definition of United Airway Disease (UAD)[10].

Exposures to airborne protein antigens (aeroallergens) cause sensitization with production of Th2-dependent antibodies, including IgE. The IgE antibodies and associated cellular responses are responsible for the allergic airway diseases, allergic rhinitis and allergic asthma. The important groups of aeroallergens are house dust mites, cockroaches, pets, pollens, and moulds and these allergens have different potential to sensitize exposed subjects [11].

A reliable method to detect the specific aeroallergen responsible for causing allergic reaction including, asthma, urticaria, anapylaxis, atopic eczema and suspected food and drug allergy is the Skin prick testing (SPT).It has been used as a primary diagnostic tool to detect type I hypersensitivity reactions and also helps in the identification of offending allergens and therefore influences therapeutic interventions, which have a significant impact on the individual's quality of life [12]

\section{MATERIAL AND METHODS}

\section{Characteristics of Study Population}

The study was conducted in the Department of Immunology and Molecular Medicine, Sher-i-Kashmir Institute of Medical Sciences, Soura and Srinagar for a period of four and a half year from January 2010 to June 2015. An informed consent was taken from all the patients for participation in the study. All the patients attending allergy and immunology clinic were subjected to detailed history, clinical examination, Complete Blood Counts, Spirometry and total serum IgE levels. A total of 555 patients consisting of 345(62\%) females and 210(38\%) males in the age group of 6 to 78 years (mean age 31.68years), were included in the study (Table 1).

\section{Skin Prick Testing}

The recommended method of prick testing includes the appropriate use of specific allergen extracts, positive and negative controls, interpretation of the tests after $15-20$ minutes of application, with a positive result defined as a wheal $\geq 3 \mathrm{~mm}$ diameter.

Skin prick test was performed using aeroallergen kit. Aeroallergens included 3 dust mite, 9 moulds, 19 pollens, 7 epithelia and 6 insects. Positive and negative controls used were Histamine and Normal saline respectively.

A drop of Allergen extract was placed on flexor aspect of forearm and then a prick was made using a sterile blood lancet. The skin prick reaction was read after 20 minutes and graded in comparison to histamine (positive control) as $1+$, $2+, 3+$ and $4+$ that is $25 \%, 50 \%, 100 \%$ and $200 \%$ of wheal induced by histamine. Only $2+, 3+$ and $4+$ reactions were labeled as positive skin reactions, due to high incidence of $1+$ reaction in the non-allergic normal persons (Figure 1). Oralanti-histamines and other drugs likely to affect SPT were withheld for seven days. Pregnant women and children less than 5 years of age were excluded from study. 

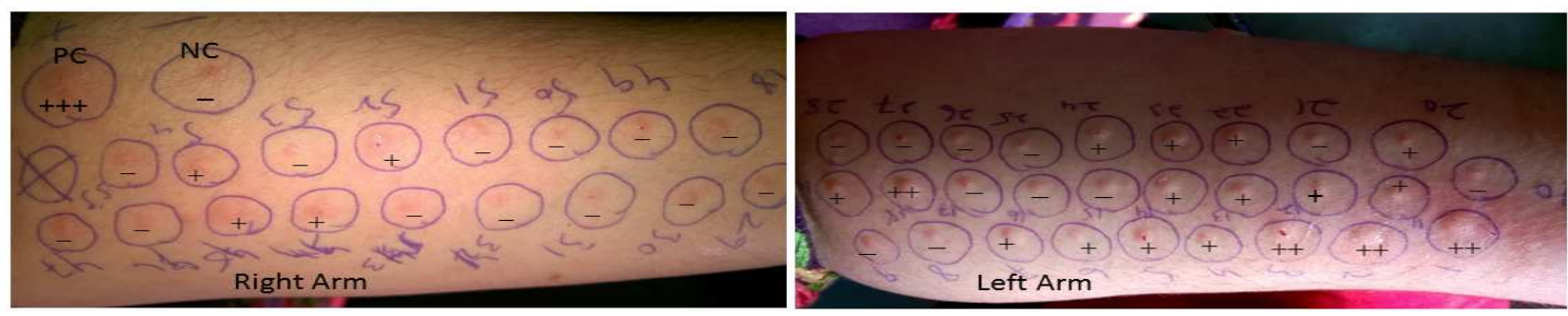

PC : Positive Control

NC: Negative Control

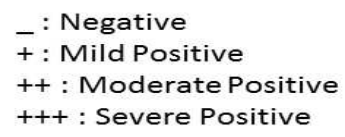

Figure 1: Representative Picture of SPT Done on Patient's Fore-Arm Showing Negative, Mild Moderate and Highly Positive Reaction to Various Aero-Allergens Along with Positive and Negative Control

\section{Statistical Analysis}

All the statistical analysis was done using SPSS software version 2.0.

\section{RESULTS}

Out of 555 patients, $210(38 \%)$ were males and $345(62 \%)$ were females, with male to female ratio of 1:1.64.All the patients were in the age group of 6 to 78 years, with mean age of 31.68 years (Table 1). Patients diagnosed with bronchial asthma were 160(28.8\%), allergic rhinitis were $342(61.6 \%)$ and having both bronchial asthma and allergic rhinitis were $53(9.5 \%)$.

Among the asthma patients, $54.5 \%$ were positive for dust mite, $30 \%$ for fungi, $72.7 \%$ for pollens, $20.2 \%$ to epithelia and $24.2 \%$ to insects' sensitizations. $63.09 \%$ allergic rhinitis patients were positive for dust mite, $29.8 \%$ for fungi, $78.5 \%$ for pollens, $35.4 \%$ for epithelia, pollens $33.2 \%$ for asthma. In the patients suffering from both asthma and allergic rhinitis $74.1 \%$ for dust mite, $38.7 \%$ for fungi, $80.6 \%$ for pollens, $41.9 \%$ for epithelia and 58\% for insects Figure 37 give us the prevalence of the different allergens among the patients. All the patients showed a poly sensitization pattern and none of the patient was mono sensitized to a particular allergen. The poly sensitization was the highest for the various pollens that were tested. Table 2 shows the $\%$ age of patients sensitized to various allergens in the asthma, allergic rhinitis and asthma + allergic rhinitis group. Sensitivity to dust mite (D-farinae and D- pteronyssinus) was significantly associated with the allergic rhinitis and asthma (Table 3); dustmites (D-farinae and D- pteronyssinus and blomia sp) and pollens (Cyanadon dactylon, Cyprus rotundus, Parthenium hysterophorus, Amaranthus spinosus, Populus, Prosopis jullifera, Chenopodium murale) were significantly associated in patients with asthma only and patients with asthma + allergic rhinitis (Table 4) ; dust mite (blomia sp) was significantly associated in patients with allergic rhinitis and allergic rhinitis + asthma (Table 5).

The incidence of allergic rhinitis was found higher in Srinagar followed by Anantnag, Budgam, Baramulla, Ganderbal, Pulwama, Kulgam and Kupwara respectively, the incidence of Bronchial asthma was found higher in Srinagar, followed by Budgam, Baramulla, Anantnag, Pulwama, Kulgam and Kupwara respectively and the incidence of both Allergic rhinitis and Asthma was found higher in Srinagar followed by Anantnag, Budgam, Ganderbal, Baramulla, Kulgam, Pulwama and Kupwara respectively (Figure 2). 


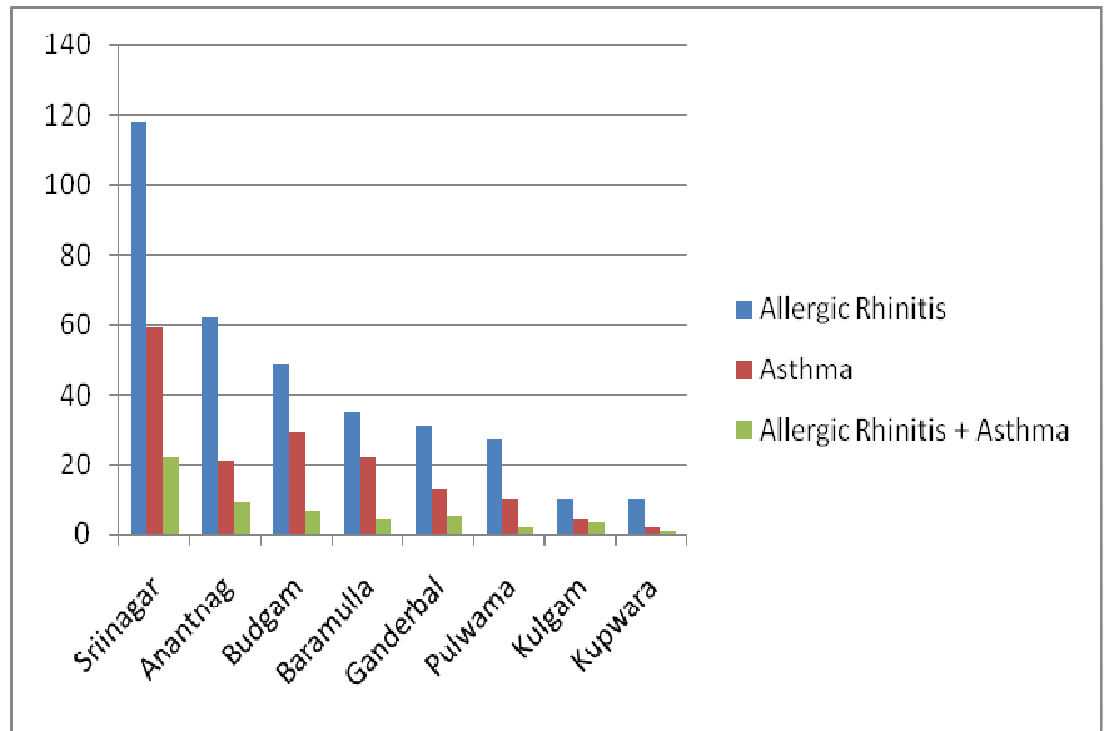

Figure 2: District-Wise Incidence of Allergic Rhinitis, Asthma and Allergic Rhinitis + Asthma

\section{DISCUSSIONS}

Poly sensitization is a clinically significant immunological phenomenon [13-21]. The increasing number of sensitizations seems to characterize the natural history of allergic patient and may represent a typical evolution of allergy. The percentage of poly sensitized patients may widely range from 20 to $90 \%$ of evaluated populations [23]. Poly sensitization may also be associated with different clinical features compared to mono sensitized patients, especially with a more impaired quality of life [22, 18]. Moreover, it has been observed that poly sensitized patients with rhinitis more frequently present associated asthma than mono sensitized ones [23].

The results of our study showed that the common sensitizing aeroallergens among patients with Allergic rhinitis and asthma were house dust mites, moulds, and animal dander, weed, tree and grass pollens. We observed a complete poly sensitization of the individuals to various allergens. None of the patients included in this study presented with mono sensitization. We also observed greater degree of poly sensitizations in patients presenting with both asthma and allergic rhinitis, as compared to patients with asthma or allergic rhinitis alone. This poly sensitization can be attributed to the cross reactivity between different allergen epitopes. It has been noted previously that allergen cross reactivity is essentially related to similar protein three dimensional structures, which causes IgE antibodies originally raised against one allergen, to bind to a similar protein in another allergen. This is also referred to as "cross-sensitization". The structural basis of cross reactivity was recently confirmed by Pfiffner et al. who reported predictions of cross-reactivity based on an iterative, motif detection algorithm. They hypothesized that cross reaction (i.e. a single type of IgE binding to two or more related motifs) was more common than co-sensitization (i.e. separate IgEs each binding to different motifs) [24].

We observed that indoor allergens like Dermatophagoides farinae, Dermatophagoides pteronyssinus as well as various pollens like cyanadon dactylon, Populus and Cyprus rotundus were more prevalent than other allergens. The higher prevalence of indoor allergens (dust mites) can be attributed to the harsh winters in Kashmir during which people are forced to stay indoors, causing exposure to these allergens. Our results coincide with a study from southwestern Iran where due to high humidity people stay indoors and hence sensitization to the indoor allergens takes place [25]. Further, due to the devastating floods in 2014 and the upcoming huge constructions, the exposure of the people to dust has further 
increased, thereby rendering them vulnerable to nasobronchial allergies.

As regards the sensitization to pollens, Kashmir is a valley surrounded by mountains and is very rich in lush greenery and forests. Due to the large variety of trees present in Kashmir, the pollens are a major aero allergen in our population, particularly during the pollination season when the number of patients presenting with nasobronchial allergies increases significantly.

The patients also showed sensitization to various epithelia as well as to insects. Sheep's wool was the most common epithelia to which patients were allergic. This can be attributed to the cold weather in Kashmir due to which people have to use woolens, and are therefore exposed to the allergen. Among insects, cockroach was the most prevalent allergen in the kashmiri population.

The nasobronchial allergies in Kashmir Valley can be attributed to poly sensitization to various indoor as well as outdoor allergens. Indoor as well as outdoor environmental exposures are major contributors to nasobronchial allergies; environmental control practices aimed at reducing these exposures are an integral component of allergy management. The management of respiratory allergy is based on allergen avoidance (when possible) [26], treatment with symptomatic drugs (such as antihistamines, inhaled, intranasal and systemic corticosteroids, bronchodilators and leukotriene receptor antagonists [27-29]) and allergen immunotherapy (AIT). Specific allergen immunotherapy (AIT) is the only therapeutic method that may have a positive impact on the natural course of an allergic disease - affecting both the development of new sensitizations, as well as clinical development, including the worsening of symptom severity and the progression of rhinitis to asthma.

\section{REFERENCES}

1. J. Jabez Christopher et al. “Computers in Biology and Medicine” 65 (2015) 76-84

2. Johansson SGO, Haahtela T. "World Allergy Organization Guidelines for Prevention of Allergy and Allergic Asthma". "World allergy organization guidelines" Available from: http://www.worldallergy.org/WAD2005/index.html. Accessed June 25,2008

3. W. A. Shaikh "Allergies in India and analysis of 1619 patients attending an allergic clinic in Bombay India."Int. Review Allergol Clin Immunol 1997; 111: 101-104

4. Meltzer EO, Blaiss MS, Derebury MJ, Mahr TA et al. Burden of allergic rhinitis: results from pedriatic allergies in America survey. J Allergy Clin Immunol, 2009; 124:S43-70.

5. S. K. Chhabra, C. K. Gupta, S. Raj pal,P. Chhabra, "Prevalence of asthma in school children in Delhi." J Asthma 1998; 25: $73-82$

6. Prasad et al. "Skin prick test, nasobronchial allergy.” j. lung India.2009; 26:3; 71-73.

7. Kumar et al, "Skin sensitivity to aeroallergens in India”, J. Indian journal of Allergy, Asthma and Immunology, 2012; 26:6771.

8. J. M.Smith. "Epidemiology and natural history of asthma, allergic rhinitis, and atopic dermatitis (eczema)" In: C Middleton, CE Reed, E D Elis et al, (Eds.) Allergy: Principles and Practice. Mosby, St. Louis; 1988:891-929.

9. C. E. Reed, E. F.Ellis, Editors. “Allergy: Principles and Practice. $2^{\text {nd }}$ ed.” St. Louis: Mosby; 1983. p. 771 7803

10. G. Passalacqua, G.Ciprandi, G. W. Canonica “United airways disease: therapeutic aspects."Thorax 2000; 55 (suppl. 2): $526-$ 
11. Nielsen GD Hansen JS, Lund RM, Bergqvist M, Larsen ST, Clausen SK, Thygesen P, Poulsen OM, IgE mediated asthma and rhinitis I: a role of allergen exposure? Pharmacol Toxicol. 2002 May; 90 (5):231-42.

12. Heinzerling L, Mari A, Bergmann KC, Bresciani M et al. The skin prick test-European standards Clinical and Translational Allergy 2013, 3:3

13. Fasce L, Tosca MA, Olcese R, Milanese M, Erba D, Ciprandi G. The natural history of allergy: the development of new sensitizations in asthmatic children. Immunol Lett 2004; 93: 45-50.

14. Fasce L, Tosca MA, Baroffio M, Olcese R, Ciprandi G. Atopic infants with wheezing start always with monosensitization. All Asthma Proc 2007; 28: 449-53

15. Arbes Jr SJ, Gergen PJ, Elliott L, Zeldin DC Prevalences of positive skin test responses to 10 common allergens in the US population: results from the third National Health and Nutrition Examination Survey. J Allergy Clin Immunol 2005; 116: 377-83

16. Craig TJ, King TS, Lemanske Jr RF, et al. Aeroallergen sensitization correlates with $P C(20)$ and exhaled nitric oxide in subjects with mild-to-moderate asthma. J Allergy Clin Immunol 2008; 121: 671-7.

17. Antonicelli L, Micucci C, Voltolini S, Feliziani V, Senna GE, Di Blasi P, et al. Allergic rhinitis and asthma comorbidity: ARIA classification of rhinitis does not correlate with the prevalence of asthma. Clin Exp Allergy 2007; 37: 954-60.

18. Bugiani M, Carosso A, Migliore E, Piccioni P, Corsico A, Olivieri M, et al. Allergic rhinitis and asthma comorbidity in a survey of young adults in Italy. Allergy 2005; 60: 165-70.

19. Peternel R, Milanovic SM, Hrga I, Mileta T, Culig J. Incidence of Betulaceae pollen and pollinosis in Zagreb, Croatia, 20022005. Ann Agric Environ Med 2007; 14: 87-91.

20. Navarro A, Colas C, Anton E, Conde J, Davila I, Fernandez-Parre B, et al. Epidemiology of allergic rhinitis in allergy consultations in Spain: Alergológica- 2005. J Investig Allergol Clin Immunol 2009; 19: 7-13.

21. Crimi P, Minale P, Tazzer C, Zanardi S, Ciprandi G. Asthma and rhinitis in schoolchildren: the impact of allergic sensitization to aeroallergens. J Investig Allergol Clin Immunol 2001; 11: 103-6.

22. Ciprandi G, Klersy C, Cirillo I, Marseglia GL. Quality of life in allergic rhinitis: relationship with clinical, immunological, and functional aspects. Clin Exp Allergy 2007; 37: 1528-35.

23. Ciprandi G, Alesina $R$, Ariano R, Aurnia P, Borrelli P, Cadario G, et al. Characteristics of patients with allergic polysensitization: the POLISMAIL study. Eur Ann Allergy Clin Immunol 2008; 40: 77-83.

24. Pfiffner P, Stadler BM, Rasi C, Scala E, Mari A: Cross-relations vs co-sensitization evaluated by in silico motifs and in vitro IgE microarray testing. Allergy 2012, 67:210-216.

25. Farrokhi1 M, Gheybi K, Movahed A, Tahmasebi R, Iranpour D etal. Common Aeroallergens in Patients with Asthma and Allergic Rhinitis Living in Southwestern Part of Iran: Based on Skin Prick Test Reactivity. Iran J Allergy Asthma Immunol April 2015; 14(2):133-138.

26. Custovic A, Wijk RG: The effectiveness of measures to change the indoor environment in the treatment of allergic rhinitis and asthma: ARIA update (in collaboration with GA (2) LEN). Allergy 2005, 60:1112-1115.

27. Marple BF, Fornadley JA, Patel AA, Fineman SM, Fromer L, Krouse JH, Lanier BQ,Penna P: American Academy of Otolaryngic Allergy Working Group on Allergic Rhinitis: Keys to successful management of patients with allergic rhinitis: 
focus on patient confidence, compliance, and satisfaction. Otolaryngol Head Neck Surg 2007, 136:S107-S124.

28. Wallace DV, Dykewicz MS, Bernstein DI, Blessing-Moore J, Cox L, Khan DA: Joint Task Force on Practice, American Academy of Allergy, Asthma \& Immunology, American College of Allergy, Asthma and Immunology, Joint Council of Allergy, Asthma and Immunology: The diagnosis and management of rhinitis: an updated practice parameter. J Allergy Clin Immunol 2008, 122(2 Suppl):S1-S84.

29. Bousquet J, Khaltaev N, Cruz AA, Denburg J, Fokkens WJ, Togias A, Zuberbier T, et al Allergic Rhinitis and its Impact on Asthma (ARIA) 2008 Update (in collaboration with the World Health Organization, GA2LEN and AllerGen). Allergy 2008, 63:S8-S160.

\section{APPENDICES}

Tables 1: Demography of Patients

\begin{tabular}{|l|c|}
\hline & Mean \pm SD \\
\hline Age & $31.68 \pm 13.29$ \\
\hline Male, n (\%) & $210(37.91)$ \\
\hline Female, n (\%) & $344(62.09)$ \\
\hline
\end{tabular}

Table 2: Comparison of Asthma, Allergic Rhinitis and Asthma + Allergic Rhinitis Patients Positive for Different Allergens

\begin{tabular}{|c|l|c|c|c|}
\hline S. No & Allergen & $\begin{array}{c}\text { Asthma } \\
\text { (\% Age of Patients Positive) }\end{array}$ & $\begin{array}{c}\text { Allergic Rhinitis } \\
\text { (\%ge of Patients Positive) }\end{array}$ & $\begin{array}{c}\text { Asthma + Allergic Rhinitis } \\
\text { (\% Age of Patients Positive) }\end{array}$ \\
\hline 1. & Dust mite & 54.5 & 63.09 & 74.1 \\
\hline 2. & Fungi & 30 & 29.8 & 38.7 \\
\hline 3. & Pollens & 72.7 & 78.5 & 80.6 \\
\hline 4. & Epithelia & 20.2 & 35.4 & 41.9 \\
\hline 5. & Insects & 24.2 & 33.2 & 58 \\
\hline
\end{tabular}

\section{Dust mite}

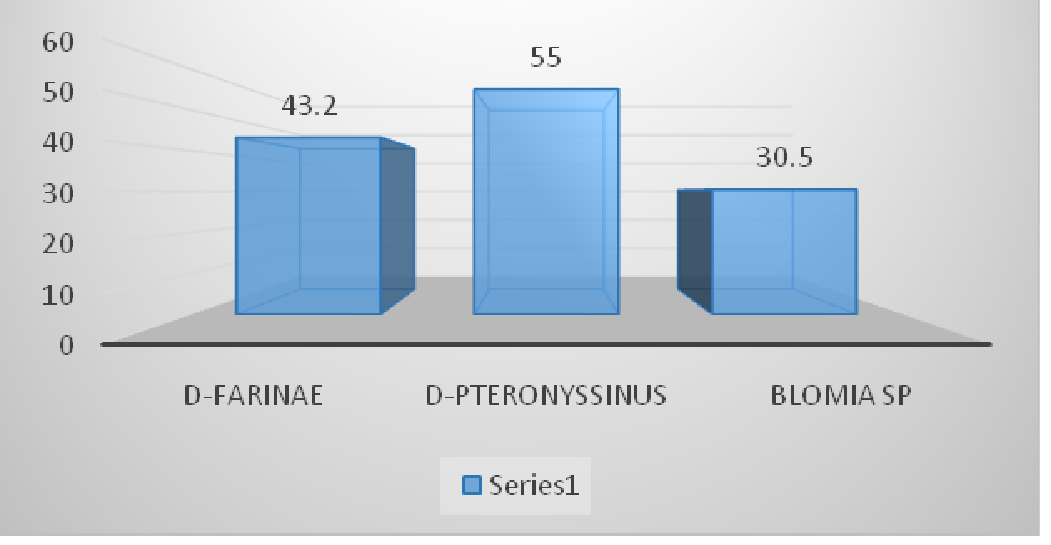

Figure 2: Aeroallergen Sensitization to Dust Mite in Patients with Nasobronchial Allergies in Percent by Skin Prick Test 


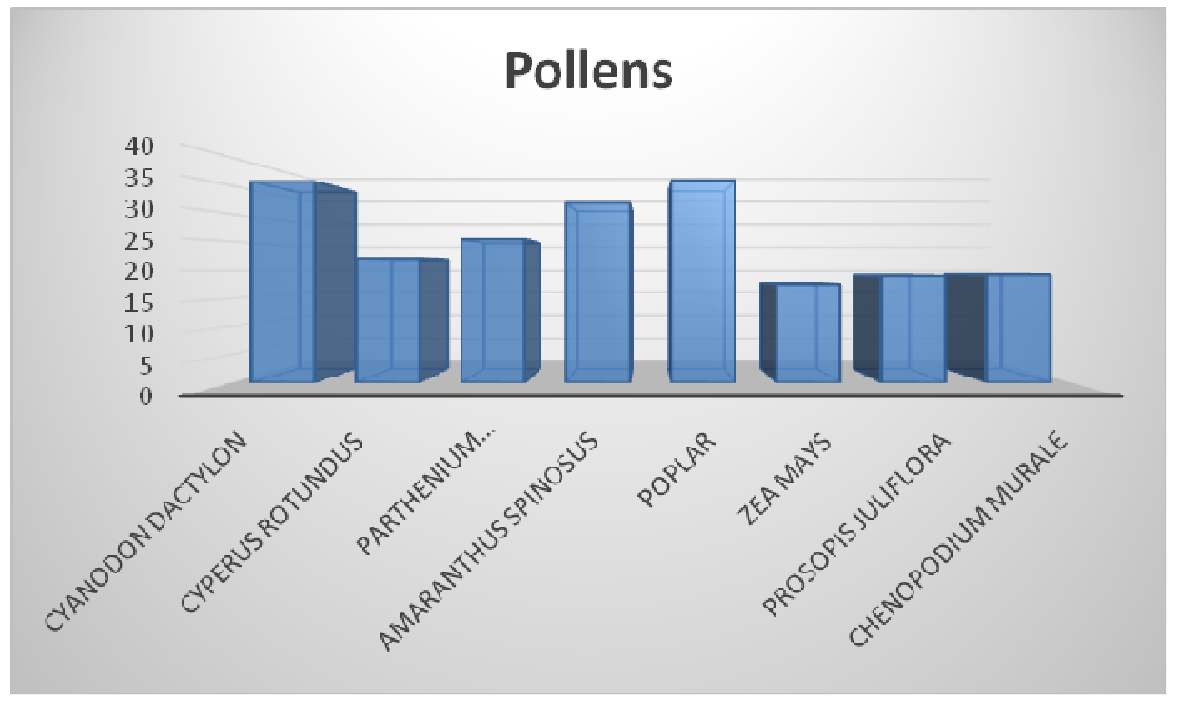

Figure 3: Aeroallergen Sensitization to Pollen in Patients with Nasobronchial Allergies in Percent by Skin Prick Test

\section{Fungi}

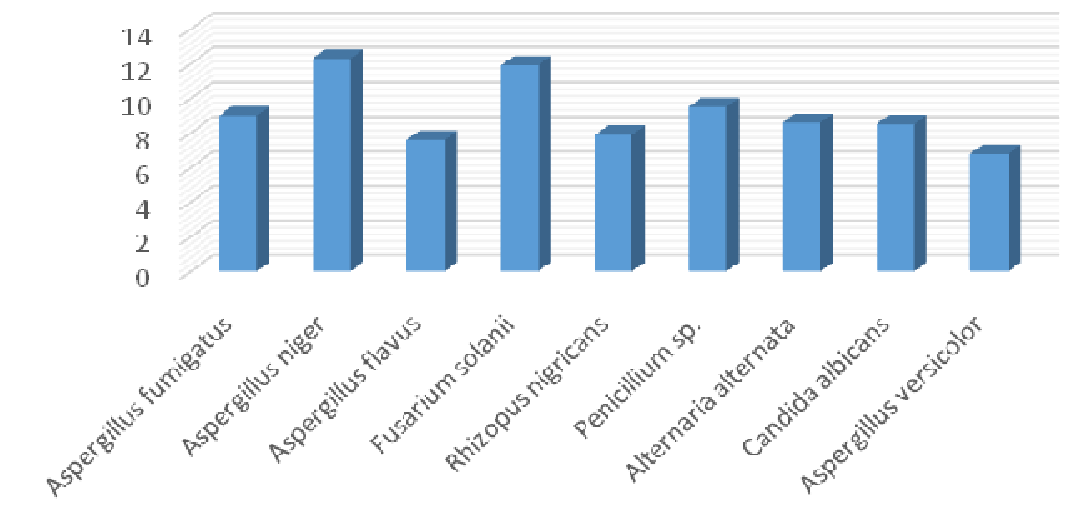

Figure 4: Aeroallergen Sensitization to Moulds in Patients with Nasobronchial Allergies in Percent by Skin Prick Test

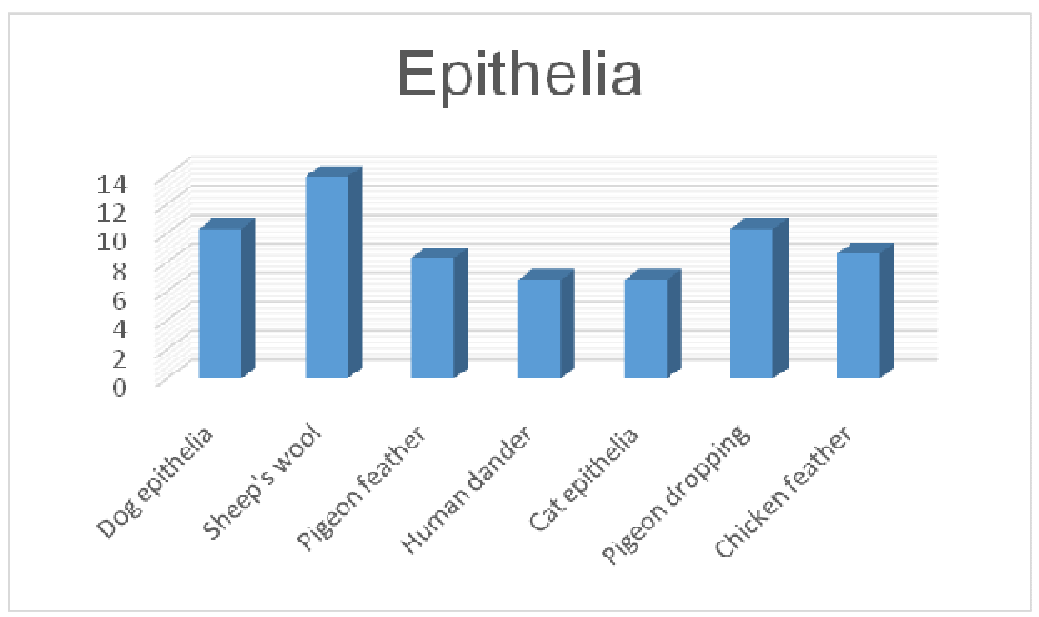

Figure 5: Aeroallergen Sensitization to Epithelia in Patients with Nasobronchial Allergies in Percent by Skin Prick Test 


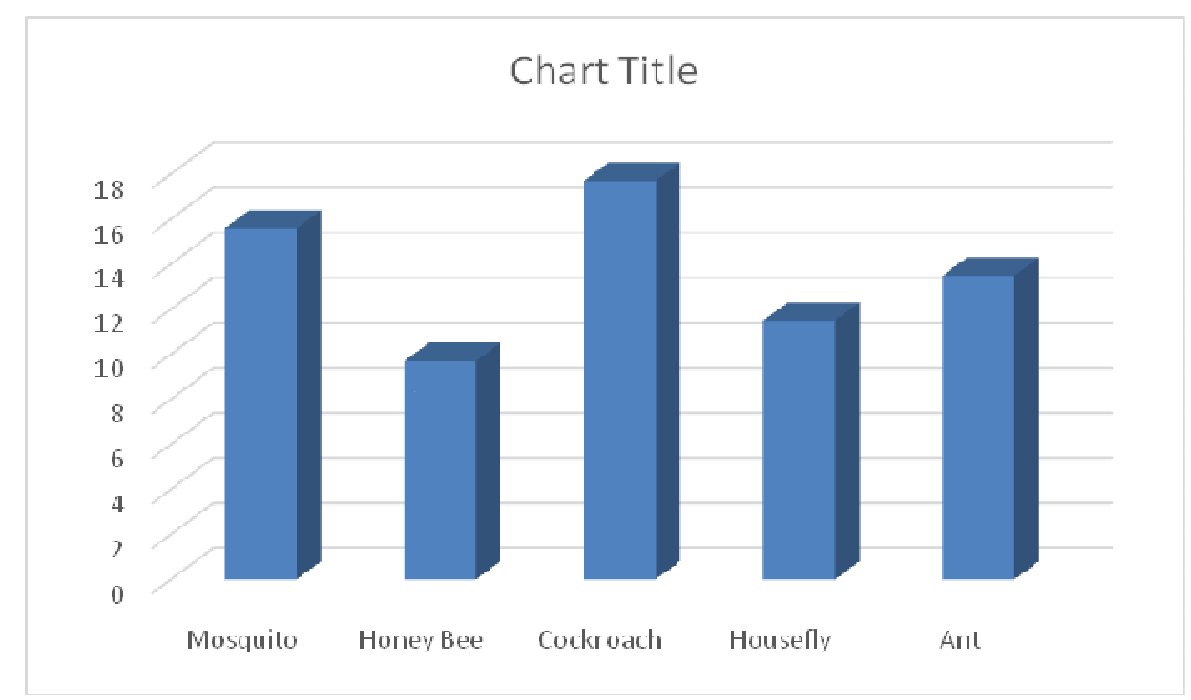

Figure 6: Aeroallergen Sensitization to Insects in Patients with Nasobronchial Allergies in Percent by Skin Prick Test

Table 3: The Prevalence of SPT Reactivity to Common Aeroallergens in Asthma \& Allergic Rhinitis

\begin{tabular}{|l|c|c|c|}
\hline \multicolumn{1}{|c|}{ Allergen } & Asthma (N= 160) & Allergic Rhinitis (N=342) & P-Value \\
\hline D-f & 50 & 151 & $0.006^{*}$ \\
\hline D-p & 73 & 197 & $0.012^{*}$ \\
\hline Blomia sp & 45 & 90 & $0.67^{* *}$ \\
\hline Cyanadon dactylon & 57 & 119 & $0.85^{* *}$ \\
\hline Cyprus rotundus & 42 & 73 & $0.22^{* *}$ \\
\hline Parthenium hysterophorus & 30 & 85 & $0.12^{* *}$ \\
\hline Amaranthus spinosus & 57 & 124 & $0.89^{* *}$ \\
\hline Populus & 83 & 115 & $0.98^{* *}$ \\
\hline Prosopis jullifera & 26 & 67 & $0.36^{* *}$ \\
\hline Chenopodium murale & 10 & 36 & $0.12^{* *}$ \\
\hline
\end{tabular}

$(* \mathrm{P}<0.05 \mathrm{~S})(* * \mathrm{P}>0.05 \mathrm{NS})$

Table 4: The Prevalence of SPT Reactivity to Common Aeroallergens in Asthma \& Asthma + Allergic Rhinitis

\begin{tabular}{|l|c|c|c|}
\hline \multicolumn{1}{|c|}{ Allergen } & Asthma $(\mathbf{n = 1 6 0 )}$ & Asthma + Allergic Rhinitis (n=342) & P Value \\
\hline D-f & 50 & 33 & $0.000^{*}$ \\
\hline D-p & 73 & 33 & $0.000^{*}$ \\
\hline Blomia sp & 45 & 27 & $0.000^{*}$ \\
\hline Cyanadon dactylon & 57 & 14 & $0.001^{*}$ \\
\hline Cyprus rotundus & 42 & 14 & $0.001^{*}$ \\
\hline Parthenium hysterophorus & 30 & 21 & $0.001^{*}$ \\
\hline Amaranthus spinosus & 57 & 12 & $0.001^{*}$ \\
\hline Populus & 83 & 17 & $0.001^{*}$ \\
\hline Prosopis jullifera & 26 & 14 & $0.001^{*}$ \\
\hline Chenopodium murale & 10 & 2 & $0.000^{*}$ \\
\hline
\end{tabular}

$(* \mathrm{P}<0.05 \mathrm{~S})(* * \mathrm{P}>0.05 \mathrm{NS})$

Table 5: The Prevalence of SPT Reactivity to Common Aeroallergens in Allergic Rhinitis \& Asthma + Allergic Rhinitis

\begin{tabular}{|l|c|c|c|}
\hline \multicolumn{1}{|c|}{ Allergen } & Allergic Rhinitis (n=342) & Asthma+ Allergic Rhinitis (N= 53) & P Value \\
\hline D-f & 151 & 33 & $0.154^{* *}$ \\
\hline D-p & 197 & 33 & $0.744^{* *}$ \\
\hline Blomia sp & 90 & 27 & $0.011^{*}$ \\
\hline
\end{tabular}


Taha Ashraf, Syed Shafia \& Zafar Amin Shah

\begin{tabular}{|l|c|c|c|}
\hline \multicolumn{4}{|c|}{ Table 5: Contd., } \\
\hline Cyanadon dactylon & 119 & 14 & $0.386^{* *}$ \\
\hline Cyprus rotundus & 73 & 14 & $0.513^{* *}$ \\
\hline Parthenium hysterophorus & 85 & 21 & $0.099^{* *}$ \\
\hline Amaranthus spinosus & 124 & 12 & $0.158^{* *}$ \\
\hline Populus & 115 & 17 & $0.874^{* *}$ \\
\hline Prosopis jullifera & 67 & 14 & $0.362^{* *}$ \\
\hline Chenopodium murale & 36 & 2 & $0.149^{* *}$ \\
\hline
\end{tabular}

$(* \mathrm{P}<0.05 \mathrm{~S})(* * \mathrm{P}>0.05 \mathrm{NS})$ 